\title{
Una Etapa Poco Conocida de la Poesía Gauchesca: de Hidalgo a Ascasubi (1823.1851)
}

\section{INTRODUCCIÓN}

Hidalgo, muerto prematuramente en 1822, había elaborado los rasgos fundamentales y característicos de la poesía gauchesca. Las pautas que sus obras sugieren prefiguran las más diversas vertientes que se habrian de transitar luego: la lírica, la satírica, la costumbrista, la épica. Por otro lado los cielitos y los diálogos se convertirían, a lo largo de muchos años, en las formas expresivas más frecuentemente utilizadas. En cuanto al sentido de su prédica, comprometida y militante, algunos de sus seguidores la llevarian a extremos que quizá Hidalgo no imaginó. Esto último no fue un hecho accidental sino que debe explicarse a la luz de la borrascosa historia política que les tocó vivir a los pueblos rioplatenses a lo largo del segundo cuarto del siglo pasado.

Cuando Hidalgo abandona la escena aún no había concluido la guerra de la Independencia. Luego sobrevendría la guerra con el imperio del Brasil; y más tarde una enconada y sangrienta guerra civil que escindiría a la Argentina en dos bandos irreconciliables. Los ecos de esta lucha alcanzaron a sentirse en el Uruguay y, en alguna medida, hasta en Brasil. Es precisamente esta época de guerra civil la que exaltaría los ánimos de los hombres de letras hasta convertir sus producciones en apasionadas armas de combate, más agresivas y contundentes aún que en los tiempos de la guerra contra la dominación española. Nadie - ni los poetas cultos ni los poetas populares- pudo sustraerse de ese destino común que se jugaba igual en trincheras, campamentos y pulperias como en hojas políticas y literarias.

Hidalgo dejó seguidores e imitadores que hicieron fortuna varia en el campo de la poesía gauchesca. Aún no los conocemos suficientemente 
bien a muchos de ellos, ya que la etapa posterior a Hidalgo es quizá la menos estudiada en lo que hace a este aspecto de nuestra historia literaria. Sin embargo en los últimos años se han realizado varios ponderables avances en las investigaciones especializadas que han permitido echar mayor luz sobre este campo. Han ido descubriéndose composiciones desconocidas y autores olvidados. En base a esos nuevos aportes nos proponemos articular aquí un panorama actualizado de la poesía gauchesca en el período que transcurre entre la muerte de Hidalgo y las postrimerías de la época de Rosas, es decir el lapso que antecede a la etapa de culminación del género. Este panorama es comprensivo del área gauchesca en su totalidad: no sólo la región rioplatense sino también el territorio brasileño de Río Grande.

\section{UN "NUEVO" Y ANÓNIMO POETA}

No había transcurrido un año de la muerte de Hidalgo, el iniciador, cuando se publicó por la Imprenta de los Expósitos, en Buenos Aires, un folleto de veintitrés páginas titulado Graciosa y divertida conversación que tuvo Chano con señor Ramón Contreras, con respecto a las fiestas mayas de 1823. El opúsculo, que carece de indicación de autor, y cuyo hallazgo fue realizado en 1968 por Olga Fernández Latour de Botas, ${ }^{1}$ es una colorida y vivaz relación en verso gauchesco de las diversas celebraciones con que en Buenos Aires se conmemoró en 1823 el aniversario de la Revolución de Mayo. Particularmente merecen atención los detalles que se ofrecen acerca del viejo teatro de la Comedia. El gaucho Jacinto Chano narra a su paisano interlocutor las embarazosas dificultades que allí tuvo que padecer por desconocimiento de las costumbres de la ciudad.

Compré un goleto en la puerta,

Dentré, y me senté en un banco:

Allí estaba entretenido,

A las señoras mirando;

Unas con los abanicos

Aunque era un pobre emponchado,

Me estaban haciendo señas,

Otras hasta con la mano;

Si me harán esto de veras,

O si estarán chanceando,

1 Véase su artículo "Una pieza olvidada de la primitiva poesía gauchesca" en las páginas literarias de La Nación, Buenos Aires, 2 de junio de 1968. 
Pensaba para conmigo,

$Y$ me estaba imaginando;

¿Qué muchachas tan corrientes!

Cuando de allí a poco rato,

Vino un moso de capote,

Estubo mirando el banco,

El ochenta y cinco dixo,

Este es mi aciento, paisano.

En seguido vino otro,

$\mathrm{Y}$ estubo mirando el respaldo,

$Y$ dixo el ochenta y seis,

Este es mi aciento, cuñado.

Ansina, de esta manera,

Me hicieron it reculando,

Cada vez más para afuera

Hasta la punta del banco;

$Y$ deay les tentó mandinga,

Para acabar de embarrarlo,

Jugar la gata parida,

$Y$ yo estaba dado al malo,

Sin tener un mal cuchillo,

¿Qué había de hacer con la mano?

Viéndome tan oprimido

Me traspasé al otro banco;

Lo mesmo me acontesió,

Pues me mamé el mesmo chasco;

Me mantuve allá en la punta

A juerza de estar ipando.

Se empezaton las comedias.

¿Qué comedias ni qué diablos!

Si yo no podía atender,

Porque estaba rebentando.

A este tiempo iba viniendo

Uno que benia cobrando;

Yo creí que era limosnero,

Porque estiraba la mano.

Le pregunté, ¿quién es este?

Al que estaba más sercano;

Es el cobrador, me dixo, 
Que agora anda rejuntando

Los goletos de los hombres, $\mathrm{Y}$ es rigular entregarlos.

¿Qué goletos son, amigo, Esos que viene cobrando?

Los del asiento, me dixo, Parece que se hace el saino; ¿Qué! ¿Usté no tiene goleto?

El que tenia lo he entregado.

Ese seria el de la entrada, Pero no el de estar sentado. ¡Pues qué! ¿EI asiento se paga?

Esa es cosa de los diablos:

Si alguno va de visita, Aunque sea infeliz el rancho, Le convidan con asiento, Con mate y con un asado. ¡Y agora aqui en las comedias

Por estar uno sentado

Les ha de pagar dos reales!

Esta obra es otra recreación del tema de los festejos patrios que ya Hidalgo abordara en su Relación de 1822. La relación entre ambos diálogos se advierte tanto en el argumento y estilo como en los personajes. Es visible que el autor hizo un ponderable esfuerzo por seguir tras las huellas de Hidalgo. La semejanza lograda debió ser su más alentadora recompensa.

Debe añadirse que estamos en presencia de un olvidado precedente de un tema después transitado con mucho éxito: las divertidas incidencias que le ocurren a un gaucho en el ámbito de un teatro, que alcanzaría su nota más alta en el Fausto de Estanislao del Campo, en 1866.

Dos años después, en 1825, aparece otro anónimo folleto en verso, de treinta y cinco páginas, con este largo título: Graciosa y divertida conversación que tuvo Chano con señor Ramón Contreras, en la que detalla el primero las batallas de Lima y Alto Perú, como asimismo las de la Banda Oriental, babiendo estado cerca de ambos gobiernos con el carácter de comisionado y ahora acaba de llegar de chasque del Sarandi. Hace varios años tuvimos la suerte de encontrar el único ejemplar que se conservaba de esta obra y la reeditamos in extenso. ${ }^{2}$

2 La primera noticia de este hallazgo la dimos en nuestro artículo "Un primitivo poeta gauchesco" en el suplemento literario de La Nación, Buenos Aires, 21 
Esta segunda Divertida y graciosa conversación, largo romance de más de mil versos, es el más extenso poema publicado hasta entonces en las letras gauchescas. A título de mero cotejo ilustrativo recordemos que los tres Díálogos de Hidalgo suman sólo 940 versos.

El tema ahora es épico. Chano, soldado de la patria, narra sus andanzas y fatigas en la etapa culminante de la guerra americana contra España. Sin engreimiento, con sencilla naturalidad, da cuenta de su participación en las victoriosas jornadas de Junín y Ayacucho, al lado de Sucre y de Bolívar, o como los llama él, ño Sucre y Don Bolívar. Oígase este animado fragmento en que Chano cuenta un pasaje de la triunfal y decisiva batalla de Ayacucho:

En el nueve de diciembre,

Lo que el sol iba rayando,

Nos formamos en batalla

$Y$ se escogió para el mando

De tres juertes divisiones

A los generales bravos

Córdoba, La Mar y Lara,

Que ya estaban chalaneados,

En esto de dar la carga,

$Y$ no anduvieron chanceando,

$\mathrm{Ni}$ mi coronel Miller,

Que mandaba los caballos.

Después de varias guerrillas

Que nos fueron calentando,

Lo que estuvimos cerquita,

Lueguito nos agachamos:

Golpeándonos en la boca,

$Y$ nos juimos sable en mano.

$¡$ Hubiera visto el tendal,

Lo que nos fuimos dentrando

Por las filas enemigas,

Haciéndonos cuerpo he gato,

Sin apartarse uno de otro!

Porque el que se haiga apartado

Ese ya no tiene cura,

de julio de 1968. Pocos meses después apareció la reedición del texto integro de este folleto. Cfr.: Félix Weinberg, Un anónimo poema gauchesco da 1825 sabre la guerra de la Independencia, Extensión Cultural, Universidad Nacional del Sur, Bahía Blanca, 1968. 
Téngase por condenado, $Y$ si corre para atrás, Se lo llevaron los diables;

Es preciso ir mii unidos

Para salir del pantano.

Yo le podría decir mucho,

Pero para hacerse cargo

De lo que es en realidá

Es menester presenciarlo.

Concluída la guerra en el Perú, Chano, cumpliendo órdenes del gobierno de Buenos Aires, se traslada a la Banda Oriental donde había comenzado la lucha por la liberación contra el dominio brasileño. Allí, junto a Lavalleja y Rivera, está presente en importantes combates como el de Sarandí, cuya relación se hace de esta manera:

Nos encontramos por fin, Del juego no hicimos caso, Con la garabina atrás, $Y$ el sable bien apretado, Sin reparar en el riesgo, Luego nos entreveramos. El choque jué mii reñido Porque ya envalentonados, De que los gauchos no valen

La pitada de un cigarro,

Amigo, se hicieron juertes;

Pero de ay a poco rato, Con el barullo en el cuerpo

Corrieron como venados.

En medio de la refriega,

En lo más acalorado,

Al oficial D. Oribe

Le mataron el caballo;

Viendo yo las circunstancias

De tan miserable estado,

Ya le presenté las ancas.

De mi fogoso gateado;

Al golpe se me trepó,

$Y$ ya seguimos matando.

Pues si por casualidá 
Por algunos de los lados

Alguno se me escapaba,

El, como iba asigurado,

Lo ensartaba desde atrás.

Ansina juimos peleando

Hasta que al fin por fortuna

Vino un pingo descarriado,

Al que luego me atraqué,

$\mathrm{Y}$ lo que estubo sentado,

Ya prosiguió por sí solo,

Como un león haciendo estragos.

Desto daré testimonio,

Porque siempre fii a su lado:

Juyeron los imperiales,

Quedando el campo sembrado

Con más de unos cuatrocientos,

$\mathrm{Y}$ después en todo el largo

Que los juimos persiguiendo,

Amigo, le daría espanto

El ver la osamenteria

Como quedaba blanqueando.

Se cogieron prisioneros

De oficiales y soldados,

Como cosa de seiscientos,

$Y$ los que hubieron quedado

Con Ventos Manuel, su jefe,

Dando chicote a dos lados,

Cogieron mas que de prisa

Como para el Cerro Largo.

Que viva la Patria, amigo,

Por lo bien que se han portado

Toditos sus generales,

Oficiales y soldados.

Conviene destacar que la realización del poema y el asunto de la guerra de la Independencia que lo motiva son coetáneos. Los separan unos pocos meses y aún, en algún episodio, escasas semanas. El tema es absolutamente original y único en nuestras letras, pues nadie hasta entonces ni después - téngase presente lo dilatado del escenario, que comprende media América del Sur, desde Perú al Plata- lo volvió a abordar. Quedaba consumado además el primer poema gauchesco épico 
de largo aliento. La narración of rece una imagen inesperada, cercana, familiar, de personajes prominentes y de episodios memorables de relieve histórico.

Debemos puntualizar ahora que existe entre la Graciosa y divertida conversación de 1823 y la de 1825 una innegable relación. En ambos folletos hay sugestivos elementos comunes: título, estructura, personajes, léxico, estilo. No es aventurado, pues, admitir que las dos piezas han sido escritas por una misma pluma. No se trata sólo del hallazgo de un par de composiciones gauchescas más sino de la aparición de un nuevo autor no advertido hasta ahora.

El hecho que señalamos es, creemos, de gran significación para nuestra historia literaria. Este nuevo autor - con méritos propios- continúa en la huella iniciada por Hidalgo. Como éste falleció en 1822 y los dos folletos fueron compuestos e impresos en 1823 y 1825 no hay posibilidades de confundir su atribución aunque el estilo es muy próximo. Pero se nos ocurre una pregunta: si estos poemas se publicaron inmediatamente después de desaparecido Hidalgo ¿no habrá publicado su autor otras composiciones en vida de aquel? Téngase presente que en las obras atribuidas a Hidalgo hay piezas de filiación dudosa y sumamente discutidas. ¿No se hallarán entre ellas algunas cuya autoría corresponda más bien al creador de estas dos Graciosats y divertidas conversaciones?

Las controversias acerca de la producción de Hidalgo carecian de la perspectiva que ahora se abre pues tenemos ya ubicado - si bien no identificado aún- un nuevo autor coetáneo, y las obras de ambos pudieron confundirse incluso hasta por el anonimato que los ocultaba. No se trata de cuestionar al llamado padre de la gauchesca sino de poner las cosas en su lugar. Aún con la posibilidad siempre abierta de que se descubran nuevas composiciones de este gauchesco anónimo, creemos que urge un minucioso y sólido estudio filológico y estilístico de los dos poemas ahora revelados y de los atribuidos sin certeza a Hidalgo. Este necesario replanteo quizá podrá develar secretos no sospechados hasta hoy.

Queda dicho que, pese a nuestros empeños, hasta ahora no hemos podido identificar al autor de estas dos composiciones. En nuestro libro ya citado hemos discutido minuciosamente esta cuestión y si bien no arribamos a conclusiones positivas, han quedado descartados varios poetas de la época, entre ellos Ascasubi, en cuanto a su posible vifculación con estos folletos. ${ }^{3}$

3 Félix Weinberg, Un anónimo poema gaucbesco de 1825 sobre la guerra de la Independencia, cit., págs. 27-33. 
Chano y Contreras, personajes creados por Hidalgo, le sobreviven largamente. Los retoma, como se ha visto, el poeta anónimo que acabamos de recordar. Pero más tarde aún ellos siguen su carrera. En varios poemas, de autores conocidos y otros anónimos, posteriores a 1828, siguen Chano y Contreras protagonizando diálogos y cartas gauchescas, hasta que los va a recoger, finalmente, Ascasubi. Todas estas obras constituyen lo que ha dado en llamarse el ciclo de Chano y Contreras, que "tiene algo de la coparticipación colectiva de numerosos escritores en una sola obra", tal como lo sostuviera el estudioso uruguayo Lauro Ayestarán al referirse a la organicidad del largo periplo de estos gauchos imaginados por Hidalgo. ${ }^{4}$

Si nos atenemos al contenido de estas dos Graciosas y divertidas conversaciones es posible afirmar que con ellas se cierra una etapa de la poesía gauchesca, en la que el nombre más destacado es, indiscutiblemente, Hidalgo. Las composiciones de esta época buscan inspiración en la lucha por la libertad e independencia y saludan alborozadas las victorias de la patria nueva. Hay también explicitadas protestas por la desigual suerte que tienen gauchos y señorones en la vida del país, y algunas notas de desaliento por las injusticias que afligen al pobrerío. Llamados a la unión, al progreso y a la ilustración pública, constituyen otros aspectos notables, como asimismo algunas descripciones costumbristas. No hay alusión alguna de tipo político militante comprometida con las diversas facciones cívicas del nuevo país.

\section{Federales y unitarios}

La etapa siguiente - que se prolongará hasta 1852- tiene un signo diametralmente distinto. Ahora es la lucha de partidos y la guerra civil. La poesía gauchesca será instrumento importante en ese combate cotidiano, de años, de décadas: rezumará odios con su peculiar arsenal de burlas y denuestos. Federales y unitarios, rosistas y antirrosistas, apelarán por igual al verso gauchesco para hacerse entender por la gente campesina, buscar adhesiones y llamar a la lucha. Casi no hay ánimo ni tiempo para otras creaciones del género que no condigan con esta militancia.

Sin olvidar los inevitables precedentes, corresponde señalar que a partir de la muerte de Dorrego y. sobre todo hacia 1830 se produce en

4 Lauro Ayestarán, "La primitiva poesía gauchesca en el Uruguay. 1812-1851", en Revista del Instituto Nacional de Investigaciones y Archivos Literarios, t. I, $\mathrm{N}^{\circ} 1$, Montevideo, diciembre de 1949, pág. 220 , 
Buenos Aires una verdadera avalancha de periódicos y hojas sueltas federales de contenido panfletario, expuesto incluso en lengua gauchesca. Si dejamos de lado multitud - aún no recopilada- de anónimas composiciones en verso, de tipo pasquinero, que circuló por aquellos años bajo la forma de cielitos, diálogos, confesiones, manifiestos, cartas y contestaciones, conviene detenerse un tanto en la combativa prensa política de repercusión popular, gran parte de la cual llenaba sus efímeras y pintorescas planas con versos gauchescos. ${ }^{5} \mathrm{El}$ Gaucho, Torito de los $\mathrm{Mu}$. chachos, El Tora de Once, La Gaucha, De Cada Cosa un Poquito, Los Mucbacbos, El Gaucbo Restaurador, son algunos títulos de esos periódicos. ${ }^{6}$

El periodista arquetípico de esas hojas fue Luis Pérez - cuyos principales datos biográficos aún son desconocidos-, quien, por lo menos hasta 1834, se consagró a exaltar la figura de Rosas. Extrañamente se pierden las huellas de Pérez casi en vísperas del ascenso de Rosas al gobierno con la suma del poder. Con la firma de Pancho Lugares, su seudónimo predilecto, escribió una gran cantidad de composiciones en lenguaje popular y también en lenguaje gauchesco, destinadas a circular entre gentes de procedencia campesina y aún en la propia campaña. ${ }^{7}$

Así dice una definitoria cuarteta suya de 1831, aludiendo a Rosas:
Ya gracias a Dios llegó
Nuestro adorado patrón,
El deseado de este pueblo,
El genio de la Nación. ${ }^{8}$

5 De un cielito federal anónimo, publicado en El Clasificador o El Nuevo T'ribuno, No 12, Buenos Aires, 31 de julio de 1830 , extraemos estos expresivos versos:

Cielito, cielo que sí,

Cielito de los leales;

Con el sartén por el mango

Ahora están los federales.

Tomado de Luis Soler Cañas, Negros, gauchos y compadres en el cancionero de la Federación, Theoria, Buenos Aires, 1958, pág. 69.

6 Para un panorama de este asunto véase Félix Weinberg, "El periodismo en la época de Rosas", en Revista de Historia, No 2, Buenos Aires, 1957, págs. $81-100$.

7 Sobre Luis Pérez puede consultarse Ricardo Rodríguez Molas, "Luis Pérez y la biografía de Rosas escrita en verso en 1830", en Historia, No 6 , Buenos Aires, octubre-diciembre de 1956, págs. 99-137; y Luis Soler Cañas, ob. cit.

${ }^{8}$ Luis Soler Cañas, ob cit., pág. 80. 
En estos fragmentos de cielitos despunta su habitual estilo:

Cielito, cielo que sí,

Cielito del aguacero,

Como potrillos relinchan

Los guapos del día primero.

Cielito, cielo del alma,

Cielito del rebencazo;

Tócales, Pancho, el violín,

Mientras yo preparo el lazo.9

Probablemente la obra más lograda de Luis Pérez sea su Biografía de Rosas, en verso, curiosa apología de las destrezas rurales y del personalismo demagógico del poderoso caudillo y estanciero bonaerense. Estos fragmentos pueden dar alguna idea de la composición:

De diez años ya en el campo

Todo gaucho lo quería,

Pues en pialar y enlazar

El rubio se distinguía.

No había trabajo por juerte

Que aquel se le resistiera;

Era popular, honrado,

$Y$ buen hijo a toda prueba.

Era cristiano parejo

$Y$ mozo sin presunción:

Amigo de sus amigos

$Y$ firme en su religión.

A la edad de catorce años

Sus padres lo dedicaron

A gobernar sus estancias

Porque capaz lo encontraron.

Cuando iban a visitarlo

Era de güen agasajo;

$\mathrm{Y}$ su conversación siempre

Recaiba sobre el trabajo.

En una sola mirada

๑ Ibidem, pág. 73. 
A los hombres penetraba, $Y$ aquel que le echaba un fallo Qué esperanzas que se errara.

De los sabios de la tierra

Güena opinión no tenía;

Estos no tienen acierto, Siempre a solas nos decía.

Estos nos han de enredar

Con sus malditas teorías;

$Y$ si no, tenga espera

Y lo verán algún día.

Estos no son hombres güenos,

Tienen mucha presunción.

¡Ojalá yo me equivoque

$Y$ que no tenga razón!

Era el patrón tan seguro

En un consejo que diera,

Como son en el salir

En el cielo las estrellas.

Lo mismo era cuando veía

Algún hombre desgraciado,

Lo tomaba de su cuenta

$Y$ ya estaba soliviado.

En su desgracia venía

De algún vicio arriagado,

Êl a fuerza de consejos

Luego lo daba enmendado.

Su modo es lindo y calmoso, $\mathrm{Y}$ al parecer, muy callado;

Pero, amigo, en los conflictos

Es osado como mil diablos.

El es noble y generoso,

$Y$ de corazón honrado,

Pero en viendo una traición

Pobre el que la haya jugado.

El aborrece al ladrón,

Al pícaro no le da lado;

Pero siempre favorece

Al paisano desgraciado.

Sabe muy bien distinguir 
Cuando el hombre hace un delito;

$Y$ si el hecho es impensado,

Êl lo ampara en un conflicto. ${ }^{10}$

Obviamente el principal valor de estos versos reside hoy en su carácter testimonial de una forma de literatura utilizada como arma de propaganda y de combate poítico.

Como excepción a la tónica general que inspira las páginas gauchescas salidas de la pluma de Pérez, encontramos una composición sin connotaciones políticas, que brinda curiosos $\mathrm{e}$ interesantes detalles $\mathrm{y}$ hasta precios del vestido masculino y femenino usado en Buenos Aires hacia 1833:

Conozco que andará usted

Muy compuesto y presumido,

Así es que yo también

Hey de bajar bien vestido.

Pues sepa, señor Don Pancho,

Que el resto todito hey echado,

Escuchemé, no se asuste.

Mire, pues, cuanto hey comprado.

En primer lugat, amigo,

Un sombrero a la moderna,

Que me costó por favor

De pesos media docena.

Un chaleco, cosa linda,

De paño-color de grana

Con solapas redondeadas

$\mathrm{Y}$ botón de feligrana.

Un fraque medio verdoso,

Con los faldones muy tiesos,

Que por más que recatié

Me costó cincuenta pesos.

Una capa que ley cuento,

Con cuello forrado en cuero

$Y$ unas borlas, cosa linda,

Que me arrastran por el suelo.

Verde yuyo es el color;

Del precio nada hay que hablar,

10 Ricardo Rodríguez Molas, ob. cit, págs. 117-118. 
Setenta pesos pidieron

$Y$ en vano fue recatear.

Gusto da el paño de doble,

Más que una suela es de grueso

$Y$ pesa como un demonio

Pues que me dobla el pescuezo.

Como podrá hacer calor

Por los muchos apretones,

Me están haciendo también

De piel blanca pantalones.

También, amigo, a mi vieja

Le hey comprado sus cangallas,

Que se las ha de estrenar

Para las fiestas mayas.

Un peinetón, cosa güena,

Más grande que una canasta,

Que di para que lo hicieran

De tres novillos las astas.

Un chal guarda de capote

Más blanco que el almidón,

Que al verlo parece seda

Aunque sólo es de algodón.

De zaraza una pollera

Con los hombros rellenados,

Zapatos de suela doble.

Con bastantes atacados.

Unas medias de mezclilla,

Un ridículo de pana,

Un cinturón amarillo,

Un par de guantes de lana.

Un añadido hermosísimo

Que yo mismo hey trabajado,

Pues diez colas de caballo

La tal trenza me ha chupado.

Un velo lleva muy lindo,

Que es lo que más me ha costado,

Pues he corrido por todo

Hasta encontrarlo prestado. ${ }^{x 1}$

\footnotetext{
11 Cati de Jacinto Lugones a Pancho Lugares, convidándolo para las fiestas mayas, en Jorge B. Rivera, La primitiva literatura gaucbesca, Jorge Alvarez, Buenos Aires, 1968, págs. 139-142.
} 
Enfrentando al rosista Pérez le salió al paso desde Cuyo otro periodista y poeta, Juan Gualberto Godoy, enrolado en las filas del partido unitario. Desde las páginas de El Corazero, de Mendoza, Godoy atacó a Pérez con sus mismas armas, esto es sin sobriedad conceptual ni moderación de lenguaje. Así esta cuarteta con que comienza una pieza dedicado al vocero rosista:

¿Hasta cuándo quieres Pancho

Escribir barbaridades?

$¿$ No ves que tus necedades

Ya no cabe en tu rancho ${ }^{12}$

Luis Pérez respondió con su artillería habitual:

Ya tenemos en Mendoza

Un famoso Corazero,

Que ha tomado la defensa

De aquellos del día primero.

Parece que es primo hermano

Del Serrano y de la Aurora,

Porque ladra como perro

$Y$ de cuando en cuando llora. ${ }^{13}$

Se entabló una curiosa polémica, hasta hace poco desconocida, entre el periódico cuyano y el periódico porteño, en la que ambos apelaron al verso gauchesco. Sin embargo, para ceñirnos a nuestro asunto, debemos obviar esa controversia para referirnos ahora a la producción poética gauchesca de Godoy, haciendo abstracción de su poesía popular, ya que con similar destreza realizó creaciones en ambos campos.

A guisa de ejemplo veamos un trecho de su Carta de un gaucbo del Pergamino al "Corazero", de 1830:

A deshoras de la noche

$Y$ en mi cocina escondido, Cordzero de Mendoza,

Estos renglones te escribo.

Todos saben en mi pago,

Que es, amigo, el Pergamino,

\footnotetext{
12 Félix Weinberg, Juan Gualberto Godoy: literatura y politica. Poesia popular y poesia gaucbesca, Solar/Hachette, Buenos Aires, 1970, pág. 195.

13 Ibidem, pág. 217.
} 
Lo que indios y federales

Han hecho, amigo, conmigo.

Yo tenia mis caballos,

Buena cría y rodeíto,

En los tiempos que Don Raus

Nos defendió de los indios.

Todo se lo llevó el diablo,

Todo, amigo, todito;

Dende que señor Dorrego

Nos quitó nuestro padrino.

El mancarrón que escapó

De las uñas de los indios,

Don Rosas lo reyunó

Y. a todos dijo este es mío.

Ahora, pa rematar la obra,

Señor Quiroga ha venido

Con ciento sesenta diablos

Que son piores que los indios.

Dispense amigo el papel,

Y la tinta con que escribo,

Que andando tan delicado

En el pago estos oficios,

No han dejado ni un tintero

En todito el Pergamino

$Y$ para que nadie escriba

Papel no hay ni pa los vicios. ${ }^{14}$

En nuestro ya citado libro hemos estudiado detenidamente los diversos problemas que suscita la creación poética de Godoy, figura injustamente relegada en nuestra historia literaria.

Hay otro motivo de interés en la obra de Godoy que se vincula con la historia de la poesía gauchesca. Durante largos años, a partir de 1864, se sostuvo que una composición suya, llamada el Corro, escrita y publicada en 1820 , era, cronológicamente, el primer diálogo de la literatura gauchesca, anterior aún a Hidalgo. ${ }^{15}$ Del folleto que contenía el Corro no se conservaba ningún ejemplar, de modo que era imposible

14 Ibidam, págs. 247-249.

15 Fue Dominguito Sarmiento quien hizo la primera afirmación en ese sentido. Cfr.: Domingo F. Sarmiento (hijo), "Don Juan Gualberto Godoy. Ensayo literario", en Correo del Domingo, " $\mathrm{N}^{\circ} 33$, Buenos Aites, 14 de agosto de 1864, págs. 616-618. 
ratificar o rectificar esa afirmación. Esto dio margen a todo género de especulaciones y polémicas. Pero ya en 1917 había advertido Ricardo Rojas que esta apasionante querella "no podrá resolverse hasta que no estemos en condiciones de analizar el hasta hoy perdido Corro del mendocino". ${ }^{16}$ A pesar de las intensas búsquedas emprendidas el folleto no aparecía y ya se lo daba por irremisiblemente perdido, cuando en 1963 tuvimos la suerte de localizar un ejemplar del esquivo Corro en la Biblioteca Nacional de Río de Janeiro. ${ }^{17} \mathrm{Y}$ resultó que este texto no es gauchesco como tantas veces se dijo sin fundamento. Ni el lenguaje, ni la combinación estrófica, guardan relación con ese género. Es, en definitiva, una composición de carácter popular -formalmente está cerca de lo español popular, es decir dentro de nuestra tradición literaria-- pero bien lejos de las peculiaridades de la gauchesca. Queda así Hidalgo firme como iniciador literario del género gauchesco en el Río de la Plata. Hemos contribuido así a poner punto final a eso que Rafael Alberto Arrieta llamó "largo proceso de conjeturas y de confusiones en nuestra historia literaria". 18

\section{LA GAUCHESCA RIOGRANDENSE}

Estimamos oportuno ahora echar un breve vistazo a la producción poética de carácter gauchesco - que corresponde al período aquí estudiado- originada en la Banda Oriental y en el estado brasileño de Río Grande, territorios que, como es sabido, integran la llamada área gauchesca.

Veamos, en primer término, algunas referencias sobre Brasil. En el sur de este país, en efecto, también afloraron profusamente versos que trasuntan las costumbres e inquietudes de los gauchos riograndenses. La llamada guerra de los farrapos (1835-1845) tuvo eco prolongado en la poesía popular, que exaltó la heroicidad de los republicanos independentistas.

16 Ricardo Rojas, Historia de la literatura argentina. Ensayo filosófico sobre la evolución de la cultura en el Plata, Guillermo Kraft, Buenos Aires, 1960, t. II, pág. 390.

17 Dimos cuenta del hallazgo en el artículo "Resurrección de un poema perdido" en el suplemento literario de La Nación, Buenos Aires, 11 de abril de 1965. E1 texto del poema Corro puede verse en nuestro libro Juan Gualberto Godoy: literatura y política, cit., págs. 137-156. En págs. 97-101 resumimos las alternativas y polémicas a que dio lugar el extravío del Corro.

18 Rafael Alberto Arrieta, "La poesía de 1852 a $1870 "$ ", en su Historia de la literatura argentina, Peuser, Buenos Aires, 1959, t. III, pág. 34. 
Liberal republicano,

Riograndense até a morte,

Hei de levar a bandeira

Até onde fôr minha sorte. ${ }^{19}$

O como enfatiza otra composición:

Eu sou o moço gaúcho,

Valente como os mais guapos;

Filho e neto de farrapos,

Republicano no mais!

Com o meu poncho de pala,

E laço e bolas nos tentos,

Vou mais ligeiro que os ventos

Por sangas e bamburrais...

O rei, montado no trono,

Tendo os ministros consigo,

Não se compara comigo,

No dorso do meu bagual;

Se êle é rei eu sou monarca!

Se êle tem cetro dourado,

Tenho rêlho prateado

E a cancha do meu punhal! 20

La estrecha vinculación entre los acontecimientos políticos de Río Grande y los del Río de la Plata tiene eco incluso en el cancionero popular:

No outro lado da linha,

Lá pra Banda Oriental,

Vou arriscar minha vida

No partido liberal.21

La lucha contra Rosas también se refleja en composiciones poéticas de la época de la campaña militar que culminatía en la batalla de Caseros.

\footnotetext{
19 Cfr.: Augusto Meyer, Cancioneiro gaxicho, Editôra Globo, Pôrto Alegre, 1959, pág. 154 .

20 Cfr.: J. Simôes Lopes Neto, Cancioneiro guasca, Editôra Globo, Pôrto Alegre, 1960, págs. 139-140.

21 Augusto Meyer, cit., pág. 168.
} 
Rosas, com sua quadrilha

De blancos em Buenos Aires,

Dizem que já armou os frailes

Contra nós.

Há de, êsse monstro feroz,

Exp'rimentar desta feita,

Aquilo que o diabo enjeita

No inferno.

E depois, mandará as tropas

A genercila Mitnoelita.

Essa guapa señorita.

Muy afamada.

Carga sêca e denodada,

Por Deus! que the hei de fazer!

E se o pai aparecer...

Passo de largo!

$O$ seu trato é bem amargo;

E somente p'ra brincar,

Gosta de fazer tocar

A Resualosa. ${ }^{22}$

La temática de la poesía gálcha es de una variedad y riqueza sorprendente para quienes no la han frecuentade y revela interesantes analogías con las composiciones de factura rioplatense. Así encontramos cantos que idealizan la vida primitiva del gaucho, el nomadismo sin atajos, el coraje personal y el espíritu de aventura. Estas cuartetas anónimas son una buena muestra de esas sugestiones:

Nos campos de minha terra,

Sou gaúcho sem patrão;

De a cavalo, bem armado,

Minha lei é o coração.

Sou valente como as armas,

Sour guapo como un leão;

22 J. Simôes Lopes Neto, cit., págs. 148-149. Los fragmentos transcriptos corresponden a una composición firmada por Francisco Marques de Oliveira, fechada en 1851. En pág. 200 de esta recopilación puede leerse otra poesía en lenguaje gauchesco del mismo autor, escrita en 1852, Ao general $D$. Manoel de Rosas, en que se hace burla del caudillo bonaerense que acababa de ser derrotado. 
Indio velho sem govêrno, Minha lei é o coração.

Quando ato a cola do pingo E ponho o chapéu do lado, $E$ boto o laço nos tentos, Por Deus que sou respeitado!

Ser monarca da coxilha

Foi sempre o meu galardão, E quando alguém me duvida, Descasco logo o facão.

Não tenho mancha nem mêdo, Năo temo inverno ou verão; Meu culto é o das raparigas $\mathrm{E}$ do mate-chimarrão.

Eu sou aquêle que disse, Depois de dizer, não nego: Achando amor de meu gôsto, Morro sêco e não me entrego.

Quando me ausento dos pagos, Isto por curto intervalo, Reconhecem minha volta Pelo tranco do cavalo.

Ninguém me pise no poncho! Pardo velho abarbarado, Tenho chilenas da prata E pala branco, bordado.

Desde guri eu já era

Um monarca abarbarado, Ninguém me pisou no poncho Que não ficasse pisado.

Pardo fôrro sem govêrno, Senhor das minhas ações, 
Sei amar gratuitamente

E punir ingratidões.

Gosto da vida do campo,

Govêrno com honra e brio;

Com um par de bolas no cinto

Não tenho mêdo nem frio. ${ }^{23}$

El asunto de las andanzas del gaucho en la ciudad aparece también representado en el cancionero riograndense:

Amigo Juca. Eu cheguei,

Da marcha um pouco delgado,

Mas os pastos da cidade

Já me têm embarrigado,

Achei encôsto e abrigo,

E mui regular aguada;

Para um homem da coxilha

Não: é má esta invernada.

Mas assim um pouco arisco,

Sempre as orelhas trocando,

Vejo coisas mui estranhas

Que me vão ressabiando.

Como abestruz na macega,

Nas ruas vivo entedado,

Sem querer, gambeteando

Para um e outro lado. ${ }^{\mathbf{2 4}}$

Las coplas gauchescas han recreado asimismo en el paisaje surbrasileño la antigua veta amatoria de la poesía popular tanto hispánica como portuguesa. ${ }^{25}$ En este orden de ideas son numerosos y variadísimos los

23 Augusto Meyer, cit., págs. 78-80.

24 Ibidem, pág. 175.

25 Veamos unas contadas muestras:

Tenho o meu cavalo baio, marchador da madrugada;

marcha, marcha, meu cavalo, vamos a ver a namorada.

Eu vi Cupido montado

no seu cavalo picaço,

de bolas e tirador,

adaga, rebenque e laço.

Fui soldado, sentei praça, 
motivos poéticos que pueden verificarse en la producción gauchesca del vecino país, mucha de la cual ha sido ya recogida. ${ }^{26}$

La acendrada tradición gauchesca de la literatura riograndense habría de culminar mucho después con el poema Antônio Chimango, de Amaro Juvenal (seudónimo de Ramiro Barcellos), publicado en 1915 y que alcanzó alli un relieve similar al que tiene el Martín Fierro en la Argentina.

\section{LA GAUCHESCA EN EL URUGUAY}

En cuanto a la antigua Banda Otiental cabe señalar que hasta 1820 las composiciones del género gauchesco - las de Hidalgo en primer lugar- expresan el patriotismo que la Revolución de 1810 despertó en todos los nativos del Río de la Plata. Más tarde los versos exteriorizan la resistencia ante la ocupación lusitano-brasileña. Decía así un cielito:

Ellos han tomado tema

De volvernos imperiales, $\mathrm{Y}$ nosotros por sistema

Que hemos de ser orientales. ${ }^{27}$

$Y$ en el Cielito del blandengue retirado, también anónimo y de la misma época que el anterior, leemos:

Cuatro bacas hei juntado

A jueza de trabajar,

$\mathrm{Y}$ agora que están gordas

Ya me las quieren robar.

$$
\begin{aligned}
& \text { sentei-me numa guarita; } \\
& \text { agora sou comandante } \\
& \text { de tôda china bonita. } \\
& \text { Quando ensillo meu picaço } \\
& \text { e boto o chapéu na nuca, } \\
& \text { tôda china que me vê } \\
& \text { fica logo bem maluca. }
\end{aligned}
$$

Tomado de Sílvio Júlio, Literatura, folclore e linguística da área gauchesca no Brasil, A. Coelho Branco Filho Editor, Rio de Janeiro, 1962, págs. 31 y 37-38.

26 Sería del mayor interés realizar un cotejo sistemático de los motivos poéticos de la gauchesca rioplatense y brasileña. Los cancionetros publicados en estos países facilitan notablemente esa labor ya impostergable. Más aún: sorprende que hasta ahora no se la haya emprendido.

27 De un poema anónimo, El cielito del dia, de 1823 , transcripto por Lauro Ayestarán, "La primitiva poesía gauchesca en el Uruguay. 1812-1851", cit., pág. 339. 
Cielito, cielo que sí,

Oye cielo mis razones:

Para amolar a los sonsos

Son estas regoluciones. ${ }^{28}$

Cielito, cielo que sí,

Baya un cielo para todos,

Mirá qué lindos patriotas

Los portugueses y godos. ${ }^{29}$

El nacimiento del Uruguay como estado independiente en 1828 hace cambiar la temática, enfilándose entonces los dardos contra los malos políticos, los comerciantes deshonestos y los periodistas venales. Tal como se lee en una anónima composición de 1832, aludiendo a esos oportunistas aprovechados:

Que con los rechupetones

Que a la pobre Patria dieron

Les ha crecido la panza

Como les crece a los cerdos. ${ }^{30}$

La figura más notable de esos años fue Manuel de Araucho, quien en 1835 publicó $U n$ paso en el Pindo, primer libro de versos que vio la luz en el Uruguay. En este volumen de inspiración neoclásica Araucho incluyó como excepción dos logradas composiciones gauchescas: Carta de un gaucbo a un proyectista del Banco de Buenos Aires y Diálogo de dos gauchos, Trejo y Lucero. En esta última se formulan quejas por los abusos de los especuladores.
¿Qué me dice ño Lucero?
¿A este estao hemos llegao?
¿Pues sabe que estamos frescos?
¿Y cómo esos desastraos
No quieren pagar el trigo
Sino a unos precios tan bajos?
Vamos al rodeo, amigo,
Que nos dé el viento del campo,
Porque ya estoy muy caliente,

\footnotetext{
28 Ibidem, pág. 329.

29 Ibidem, pág. 211.

30 Ibidem, pág. 365.
} 
Y puede tentarme el diablo,

De irme al pueblo agora mismo,

$\boldsymbol{P}$ con un garrote, a palos,

Comenzar por los del pan

$\mathrm{Y}$ acabar con los quebraos. ${ }^{31}$

Dice Ayestarán que la poesía gauchesca uruguaya alcanzó su máxima tensión con la llamada "guerra grande", esto es el período 1838-1852. La mayor parte de la producción de esta época es anónima y la línea política está escindida en dos bandos, colorados y blancos, los que apoyan al gobierno de Montevideo y los que siguen a Oribe y su gobierno del Cerrito. Burlas, amenazas y desafíos constituyen la esencia de esa porfiada poesía de combate. Esos episodios están íntimamente relacionados con la política argentina. Rosas, por un lado, y sus adversarios proscriptos en el Uruguay, por otro, fueron también protagonistas de esos sucesos. No debe sorprendernos, pues, que el poeta gauchesco de mayor relieve de la época fuera el argentino Hilario Ascasubi, sobre cuya fecunda actividad nos ocuparemos en seguida.

Debemos dejar claramente establecido, desde ya, que contrariamente a lo que suele creerse, en esa época de duras luchas entre rosistas y antirrosistas los versos gauchescos - convertidos en poderosas armas de guerra - no fueron exclusividad de los partidarios de Rosas. Sus adversarios también, y no por cietto esporádicamente, apelaron a este estilo campestre. Todo ello demuestra que el habitante de la campaña rioplatense no estaba identificado masiva y definidamente con una divisa, pues se trataba de ganarlo para uno u otro bando. Es ya temerario afirmar que el gaucho estuviera enrolado unánimemente bajo el estandarte federal, puesto que, por ejemplo, los soldados de Lavalle eran también en su mayoria de extracción campesina. Por lo demás tampoco tesulta cierto que los poetas puebleros no rosistas fueran insensibles a las quejas y sufrimientos del gauchaje. $\mathrm{Y}$ casi por definición, no podía ser de otra manera: la poesía gauchesca de más trascendencia expresaba desde los tiempos de Hidalgo las injusticias, olvidos y miserias que padecia ese grupo social.

Ascasubi - como se verái más adelante- frecuenta la entonación de protesta social que culminaría más tarde con el Martín Fierro. Hemos hecho ya alusión a Godoy, poeta unitario de Mendoza. También deben recordarse numerosas hojas sueltas con cielitos unitarios. $Y$ en Montevideo, precisamente, un grupo de exilados publicó el periódico El Grito

31 Manuel de Araucho, Un paso en el Pindo, Imprenta de los Amigos, Montevideo, 1835, pág. 183. 
Arjentino, de 1839, en cuyas páginas aparecieron varias incisivas composiciones gauchescas en las que además de comentar los sucesos políticos del momento, se formulan agudas apreciaciones de carácter social y económico que aluden al acaparamiento de tierras por los grandes estancieros que apoyaban a Rosas, como los hermanos Anchorena; la desvalorización de la moneda; el decaimiento del comercio bonaerense; y otros temas análogos, siempre con referencia al empobrecimiento de la gente campesina. ${ }^{32}$ Este semanario -que tenía como redactores a Valentín Alsina, Juan Bautista Alberdi, Miguel Cané y Luis L. Domínguez, entre otrosse propuso expresamente acercarse a los habitantes de las provincias del litoral y de la campaña bonaerense a cuyo efecto se montó una buena organización clandestina de distribución y consta que en efecto llegó a las manos de muchos hombres de campo. ${ }^{33}$

\section{Ascasubi en Montevideo}

Veamos ahora algunos aspectos significativos de la obra poética desarrollada por Ascasubi durante su exilio en Montevideo. Vamos a obviar detalles de su vida novelesca reconstruída por su biógrafo Manuel Mujica Láinez. ${ }^{34}$ Entolado Ascasubi desde joven on las filas del partido unitario es encarcelado en Buenos Aires por las autoridades rosistas y luego fuga a Montevideo. Vivió en la capital uruguaya entre 1832 y 1851. A poco de arribar allí —donde aún seguía vigente el verbo y la fama de Hidalgo- resolvió seguir tras la huella de la poesía gauchesca. Fue la gran decisión de su vida pues de ahí en más Ascasubi sólo utilizaría para expresarse el verso gauchesco.

En los bravos y duros tiempos de la lucha rioplatense entre rosistas y antirrosistas, Ascasubi, sin desmayos, estuvo presente con sus versos, ora satíricos, ora inflamados, pero siempre aguerridamente militantes de una causa cívica que él entendía era la de los principios de libertad y civilización. A pesar de que muchas veces la temática que abordó era de tintes más que sombrios, nunca dejó de apelar a los más ingeniosos recursos de la picardía criolla. Quizá esto sea una de las claves que expliquen la comunicatividad y lozanía que emanan de sus poesías a más de un siglo de escritas.

32 Los textos de ocho piezas gauchescas publicadas en El Grito Arjentino pueden verse en Ricardo Rodríguez Molas, "Elementos populares en la prédica contra Juan Manuel de Rosas", en Historia, № 30, Buenos Aires, enero-marzo de 1963, págs. 69-101.

33 Félix Weinberg, "El periodismo en la época de Rosas", cit., págs. 90-91.

34 Cfr.: Manuel Mujica Láinez, Vida de Aniceto el Gallo, Emecé, Buenos Aires, 1943. 
Ascasubi prodigó sus versos gauchescos en periódicos - como El Gaucho en Campaña, de 1839; y El Gaucbo Jacinto Cielo, de 1843- y en incontables folletos y hojas sueltas. De pocos escritores de la época podrá decirse con más propiedad que de él que fue un guerrillero de la pluma. Su público lector no eran sólo los pueblos ilustrados de Montevideo sino también el pobrerío de la ciudad y la gente de la campaña. Que tuvo repercusión su prédica en lenguaje gauchesco lo prueban las numerosas cartas y contestaciones en verso que recibía de anónimos lectores y que él mismo se encargaba de publicar en la prensa montevideana.

El nivel artístico que alcanzó Ascasubi en sus obras le colocan en el sitial más alto de la poesía gauchesca de la época. La espontaneidad y frescura de sus versos están por encima de todos sus coetáneos. Además Ascasubi era un poeta cuidadoso de las formas convencionales del género y esto se refleja en la esmerada elaboración de los versos. Es más: sus poesías revelan la riqueza de un chispeante ingenio, que transitó por senderos inesperados y sorprendentes en cuanto a temas e imágenes. $\mathrm{Sj}$ bien utilizó preferentemente el romance para expresarse, apeló con frecuencia a otras formas tradicionales rioplantenses como el cielito y la media caña.

¿Cuál fue la temática que abordó Ascasubi en esos años del exilio montevideano? Desde luego la guerra, la llamada "guerra grande" y el sitio de la capital oriental; las batallas que libraban rosistas y antirrosistas en los campos del litoral rioplatense; el gobierno del dictador de Buenos Aires; la intervención anglo-francesa en el Plata... ${ }^{35}$

Sus poesías zumbonas generalmente utilizan el diálogo entre dos gauchos para incursionar en la más candante actualidad política. Los interlocutores sue aparecen con más frecuencia son Paulino Lucero, Jacinto Cielo, Ramón Contreras -éste resurrección del personaje creado por Hidalgo-, Juan de Dios Oliva, Martín Sayago, etc.

Aparecen también partes de guerra en versiones naturalmente burlescas, como el que el general Echagüe habría enviado a Rosas con motivo de una derrota federal, y que comienza así:

¡Ay, Juan Manuel, qué te cuento!

Nuestro ejército afamado

Mandinga se lo ha llevado

Al infierno en un momento. ${ }^{36}$

\footnotetext{
35 La producción montevideana de Ascasubi está recogida en su libro Paulino Lucero, cuya primera edición data de 1853. Para nuestro trabajo utilizamos y citamos la reedición de Estrada, Buenos Aires, 1945.

36 Hilario Ascasubi, Paulino Lucero, cit., pág. 63.
} 
En otros casos hay cartas en verso dirigidas a Rosas, a estadistas y diplomáticos europeos, o simplemente a desconocidos campesinos de las provincias de Buenos Aires y Entre Ríos y del Estado Oriental. Hay por allí una breve historia del gobierno de Rosas, ${ }^{37}$ y también una curiosa crónica rimada acerca de los orígenes de los partidos colorado y blanco del Uruguayys cuya evolución está estrechamente ligada a acontecimientos políticos argentinos.

Las mil alternativas de esa guerra que le tocó vivir a Ascasubi como un protagonista más están descriptas a veces con lujo de detalles. La ironía, el guiño, la burla, asoman como recursos infalibles para alentar a los soldados de su causa y descalificar al enemigo. Hay algunas páginas sombrías, teñidas de estremecido hotror, como la escena del degüello de un unitario por un mazorquero, pero que no dejan de tener el improntu burlesco: sonrisa y grito se aúnan en un juego desgarrador de tragedia y sarcasmo.

A pesar de estar inmerso en esa guerra sin cuartel, Ascasubi no perdió de vista el futuro de su patria. En varios pasajes de poemas suyos encontramos expuestos sus anhelos de paz, conciliación y organización nacional.

Creo que de esta ocasión concluirá la destrución, la miseria y la aflición de toda la población: y también la aspiración de cualquier bando o fación, si hacemos la reflexión, que nuestra infeliz Nación al concluir el pericón se halla sin ponderación más pelada que un pelón, sin un solo patacón,

37 Ibidem, págs. 318-321.

s8 Véase la poesia titulada Juan de Dios Oliva y otros dos gauchos orientales platicando, de 1843, en Ibidem, págs. 104-141. Una nota de Ascasubi advierte que "todo lo que refiere esta composición es exactamente histórico". El interés de esta crónica se ve corroborado por el hecho de haber merecido una reedición por separado -en folleto- cuarenta años después de su publicación original. Cfr.: Hilario Ascasubi, Juan de Dios Oliva y otros dos gauchos orientales platicando el día 11 de junio de 1843 en el compamento del general Don Frutos Rivera. Romance histórico. (Orijen de los partidos colorado y blanco), Imprenta a vapor de El Ferrocarril, Montevideo, 1884; cit. por Eneida Sansone de Martinez, La imagen en la poesia gaucbesca, Facultad de Humanidades y Ciencias, Universidad de la República, Montevideo, 1962, pág. 397. 
por la sencilla razón

que en esta revolución

le han dado sin compasión

¡tantísimo manotón!...

Pero. . pase el nubarrón.

Venga la paz y la unión.

$Y$ por San Pascual Bailón

y la Pura Concepción, santos de mi devoción, que echo al infierno el latón

y me afirmo a un azadón, gritando de corazón:

¡Viva, viva la fusión,

y viva la constitución! 39

También se puede rastrear su visión del progreso nacional -a través del comercio, de la inmigración y de la industria- en lo cual coincide con los ideólogos liberales del exilio.

Y estos pueblos, a la vez, por más que Rosas se aflija, se le han de alzar a la fija colijiendo su interés.

Luego, a estos puertos verés, que de Uropa en derechura se vienen con su fatura las gentes y barquería, y correrá pesería como haberá baratura.

De consiguiente vendrán a levantar poblaciones gentes de todas naciones, que sus familias trairán, y se desparramarán por los campos y ciudades; y hasta en las inmensidades de costas del Paraná

39 Hilario Ascasubi, Paulino Lucero, cit., págs. 222-223. 


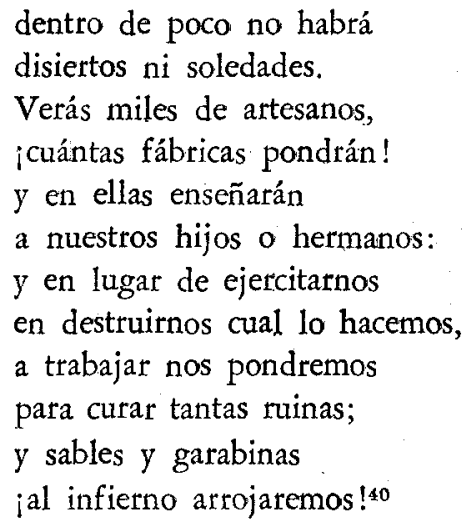

No es insensible Ascasubi a las penurias y sufrimientos que la guerra causa al gauchaje, "hombres de mi condición", como los llama en algún verso.

Los que tienen afición al suelo y al borbollón, y hoy echan tragos de ron a costa de una porción de hombres de mi condición, que soy paisano lerdón; y que en esta confusión, de pelearnos con tesón he tenido un apretón, y he vendido hasta el facón por yerba, pan o jabón: y que al fin en un rincón, con el suelo por colchón estoy sin medio y flacón, rotoso, sucio y barbón, contemplando un familión macilento y delgadón, y lamentando tristón ¡tanta vaca y mancarrón que me han hecho humo al botón!

Aunque ando con aprensión

10 Ibidem, págs. 201-203. 
que antes de la conclusión, de balde estoy ariscón, después de tanto arrejón, que algún chumbo o perdigón me estire en un albardón, y patitieso y panzón de ahí me tiren a un zanjón, como han tirado a un montón de criollos que siempre son los pavos de la función, espichan como un ratón sin pater-noster ni Kirieleysón. ${ }^{41}$

La discriminación que se hace en el trato a los gauchos está reflejada a su vez en estos versos de 1833 :
Así de la paisanada
los puebleros con razón suelen teírse, porque saben que los gauchos siempre son los pavos que en los custiones quedan con la panza al sol.

$Y$ si no, vaya por gusto en cualesquier aflición

o atraso que le suceda, y procure la ocasión de alegarle a un gobernante, a quien usted lo sirvió con su persona y sus bienes hasta que se acomodó; vaya y pidale un alivio. . ¿Y qué le daban? ipues no!

$\mathrm{Ni}$ bien llega usted al umbral, le sale algún adulón atajándole la entrada y haciendo ponderación de que se halla Vuecelencia muy lleno de ocupación,

41 Ibidem, págs. 222-224. 
porque le está dando taba

algún ricacho, o dotor,

- la señora fulana,

o el menistro, o qué se yo

todas las dificultades

que pone con la intención

de cerrarle la tranquera

a cualesquier pobretón;

y si usted ve que lo engañan,

y se mete a rezongón,

le largan cuatro bravatas

y lo echan de un repunjón

cuando menos, que otras veces

le acuden con un bastón

a medirle las costillas

sin más consideración. ${ }^{42}$

Estimamos oportuno insistir sobre este aspecto de la poesía de Ascasubi, hasta ahora no tomado en cuenta suficientemente. En su producción del exilio hay numerosas referencias a las coetáneas penosas condiciones de vida de los gauchos. Esto, por un lado, tiene el valor de un testimonio que desmiente las frecuentes e imprecisas alusiones a la existencia, antes de Caseros, de una supuesta "época de oro" del gaucho; $y$, en segundo témino, es un importante y olvidado precedente de la poesía de denuncia social, que más tarde sería transitada con mayor éxito y repercusión por otros poetas, especialmente por José Hernández. ${ }^{43}$

La declarada fidelidad de Ascasubi hacia los gauchos está expuesta en una "carta" de Jacinto Cielo, de 1843:

42 Ibidem, págs. 19-21.

43 Merece analizarse con detenimiento una sugestiva coincidencia - hasta ahora no señalada, que sepamos- en las actitudes sucesivas de Ascasubi y Hernández hacia los gauchos. Ambos condenan las injusticias de que aquéllos son víctimas, refiriéndose esta crítica a acontecimientos coetáneos - en un caso la cuarta y quinta década del siglo xIx; en el otro, la octava década-; en cambio idealizan los tiempos pasados. Pero hay un disentimiento importante: para Hernández el áureo pasado gauchesco es obviamente la época de Rosas, es decir el sistema político que Ascasubi combatió entre otros motivos porque, a su entender, usufructuaba las penurias de los gauchos. Ascasubi, en su Santos Vega, remite a un pasado mucho más lejano - postrimerías del siglo xviII y principios del xrxlos supuestos días venturosos del gauchaje. Cabe preguntarse si es que realmente existieron los paradisíacos tiempos del gaucho que ambos evocan. ¿No será que su situación concreta se asemejó más bien a lo largo de los años a la que Ascasubi y Hernández sucesivamente denuncian como injustas realidades? Sobre este asunto véase Ricardo Rodríguez Molas, Historia social del gaucho, Marú, Buenos Aires, 1968 , y se apreciará que no todo tiempo pasado fue mejor. 
Yo siempre soy muy clarito:

y ¿a qué he de andar con rodeo

para esplicar mi deseo?

¿No es ansí, compañerito?

Mi papel es peticito,

pero es gaucho y han de ver

que al Diablo le han de correr

en cuanto a decir verdades;

porque no hay dificultades

que me puedan encoger.

Siendo ansi, yo he de rumbiar

por la senda que empecé,

, sin ladiarme, pues ya sé

aonde debo enderezar.

Si llego a desagradar

no ha de ser a la gauchada. ${ }^{44}$

La puntualización de que el lenguaje campesino rioplatense es diferente del habla culta urbana aparece en varios pasajes:

Deje que allá el dotoraje

se pronuncie en lo profundo,

que los gauchos en el mundo

tenemos nuestro lenguaje. ${ }^{45}$

O como dice en otro lugar, a propósito de la recreación literaria de la lengua gauchesca:

Luego, patroncito, intento
escrebir a lo paisano,
y en estilo americano
decir todo lo que siento. ${ }^{46}$

Queremos subrayar que a pesar de lo efímero y vulgar del material que Ascasubi utilizó en su guerrilla cotidiana, muchas veces su chispeante ingenio y la gracia del arte ha dotado a sus versos de un perdurable y singular relieve. Dos ejemplos bastarán. En el primero, se verá la utiliza-

\footnotetext{
4 Hilario Ascasubi, Paulino Lacero, cit., págs. 166-167.

15 Ibidem, pág. 166.

40 Ibidem, pág. 294.
} 
ción metafórica del lenguaje del truco - uno de los más populares juegos de naipes en el Río de la Plata - para narrar un combate librado en el Uruguay entre los generales Rivera y Echagüe en 1839:

En fin, dende el Uruguay

nos vinimos barajando,

y la jugada empezó

del Uruguay a este lao.

Nos traiban una empalmada,

y nosotros descuidaos

cortábamos ande quiera,

y así nos fueron tantiando

creyendo ponerse en güenas,

hasta que dende el Durazno

les conocimos el juego;

de suerte que comenzamos

a quererles a la fija,

pues para eso asiguramos

en todas manos el dos.

¡Don Frutos! ¡háganse cargo,

si flor que tiene ese triunfo

puede retrucarla el diablo!

Por fin así nos vinimos

nosotros siempre falsiando

con un punto cualquierita,

hasta que los igualamos,

y acá por Santa Lucía

ya nos pusimos a tantos.

En esta disposición, de los dos lados cuajamos una flor rigularita, y ellos cuanto la orejiaron al instante un contraflor vanidosos nos echaron.

Haciéndonos los petizos nosotros nos achicamos, para dejarlos venir

$y$ en el truco revolcarlos, que es donde luce el poder.

Por supuesto, nos jugaron

carta grande en la primera; 
pero ahí no más la empardamos cantándoles iflor y truco! con todo el dos, por si acaso... ¡Retruco!... nos respondieron queriendo largar el gaucho. ¡Oigalé a los embusteros! les dijimos... ¡vale cuatro! a que no aguantan maulones... y medio les amostramos la carta por la orillita. ¡Qué aguantar! ¡ni por los diablos!

Se jueron a la baraja al ver el dos coloriando, $y$ han ido a dar al infierno; y se hallan tan atrasados que ahora. . ¿cuándo nos alcanzan, si sólo nos falta un tanto? $y$ ese en el primer envite fijamente lo ganamos. ${ }^{47}$

El segundo ejemplo, acaso más feliz por lo insólito, es una descripción de un barco a vapor hecha por un gaucho con expresiones e imágenes de tierra firme, pampeanas, que le son propias.

Pues mandaton embarcar de un modo tan redepente, que fue rejuntar la gente: y al momento de mandar,

Como aguacero a la costa la botería acudió, y el criollaje ahi se juntó como manga de langosta.

De ahí empezaron a echar viajes al barco a menudo, y en el bordo como pudo nos hizo despartamar...

47 Ibidem, págs. 46-48. 
Del pértigo a la culata de un barcazo roncador, ñato viejo y rodador a impulsos de una fogata:

Cosquilloso a una ruedita que de atrás un marinero se le prendió a lo carnero, haciéndole colita.

Pero, paisana. . ¡qué cosa de barco tan maquinal! $y$ grandote el animal de una manera asombrosa.

Oiga, le relataré la laya de barco que era: que no es fácil, aparcera; pero, en fin, me amañaré.

Era un barco. . . itamañazo! de madera de mi flor, y tendría de largor como dos tiros de lazo.

En la barriga tenía un pozo, donde se apiaba la gente que trajinaba en pura carbonería.

Arriba los comendantes rodeaos de la oficialada, y mucha marinerada, con sombreros relumbrantes,

Que a unos horcones tan altos, que en las nubes se perdían, por unas cuerdas subían de tropel y dando saltos.

Abajo había cuarteles y corrales y galpones; 
y encima grandes cañones

con rondanas y cordeles.

$\mathrm{Y}$ un cañuto jtemerario!

enterrao yo no sé cómo

en lo más ancho del lomo,

y más allá un campanario:

$Y$ luego en cada costao

una rueda con aletas,

que no he visto ni en carretas

de esa laya de rodao.

Viese, aparcera, al montar, ¡qué julepe y qué jabón

nos pegó una quemazón

que abajo entró a reventar!...

$Y$ ver salir apuraos

como avestruces corridos...

los hombres, que a unos chiflidos

subían todos tiznaos.

Yo me empecé a refalar

el poncho para aliviarme,

y estuve por azotarme

como carpincho a la mar.

Pero supe que de intento prendían abajo el fuego, $y$ vi a un oficial que luego se puso a vichar atento;

$\mathrm{Y}$ en cuanto por el cañuto

vido salir la humadera, le aflojaron, aparcera, y echó a correr ese bruto.

A dos laos, y relinchando, campo ajuera salió al mar, aonde empezó a bellaquiar: y ya nos juimos echando. ${ }^{48}$

48 Ibidem, págs. 369-372. 
La sola lectura de las poesías de Ascasubi explica el éxito que alcanzó en su tiempo y la popularidad y simpatía que rodeó a su nombre.

Sarmiento, quien visitó a Ascasubi en la capital uruguaya en 1846, dijo de él que era un "bardo plebeyo, templado al fuego de las batallas", que explotaba con felicidad aquel "género popular [gauchi-político] que traduce en acentos mesurados las preocupaciones de las masas". ${ }^{49}$

En 1853 recopiló Ascasubi la mayor parte de sus versos del exilio montevideano en dos volúmenes caratulados Trobos de Paulino Lucera.50 Allí se encontrará una cantera riquísima para el estudio de toda una época de la literatura gauschesca que él personafica, ya que reinó solo, sin rivales que pudieran acercarse siquiera al nivel artístico que él impuso.

La crítica literaria coetánea valoró con simpatía su obra y le alentó en la empresa. Es llamativo que un hombre como Florencio Varela saludara alborozado la aparición de cada folleto de Ascasubi. Y es precisamente Varela, formado en el culto riguroso del neoclasicismo, quien señala el carácter costumbrista de la obra de Ascasubi. "Los versos de Ascasubi -escribe Varela en 1846 - son como los cuadros de Murillo o de Rubens: el que los ha visto una vez reconoce el colorido, el estilo, donde quiera que se encuentren otros, sin necesidad de que le digan el autor... En la composición que hoy anunciamos - agrega- campean las dotes que el señor Ascasubi ha mostrado otras veces en este género de poesía: suma variedad y propiedad en las descripciones, movimiento realmente dramático en la narración, versificación fluidísima $\mathrm{y}$, sobre todo, una verdad de colorido y una propiedad de lenguaje y estilo que hace de sus composiciones el más perfecto retrato del gaucho del Río de la Plata". 51

Si bien es la más celebrada - y también abrumadora en número-, no toda la poesía ascasubiana del exilio se mezcló necesariamente en la pólvora de las trincheras y de los campamentos militares. Hay también poesía de otra intención. Es la poesía puramente costumbrista y de

49 Domingo F. Sarmiento, Viajes, Hachette, Buenos Aires, 1955, t. I, págs. 124-125.

50 Cfr.: Hilario Ascasubi, Trobos de Paulino Lucero o Colección de poesias campestres desde 1833 basta el presente ( 2 vols.), Imprenta de la Revista, Buenos Aires, 1853. Dos décadas más tarde reeditó esta obra con el título de Paulino Lucero o Los gauchos del Río de la Plata cantando y combatiendo contra los tiranos de las Repúblicas Argentina y Oriental del Uruguay (1833 a 1851), Imprenta de Paul Dupont, Paris, 1872. (Es el volumen III de sus Poesias completas.)

51 Cfr.: Félix Weinberg y colaboradores, Florencio Varela y el "Comercio del Plata", Instituto de Humanidades, Universidad Nacional del Sur, Bahia Blanca, 1970 , págs. 274. 
evocación del pasado, desligada de las urgencias y sombras de la acuciante actualidad.

Por una parte produjo, en esa corriente, una Completa relación de las fiestas civicas del aniversario de la jura de la Constitución Oriental, ${ }^{22}$ poema fechado en 1833, que sigue las pautas impuestas por Hidalgo en su Relación de las fiestas mayas de Buenos Aires en 1822 y por la anónima Graciosa y divertida conversación de 1823. La relación de Ascasubi - el primer poema importante que escribiera en el Uruguay- es una colorida y ágil descripción de las festividades con que el pueblo oriental celebró su fecha patria.

Pero la obra de mayor ambición en este ámbito alejado del inmediato compromiso político es su Santos Vega. La primera versión, parcial, de este famoso poema, fue publicado en Montevideo en 1850 con el título de Los Mellizos. Como es sabido la edición definitiva está datada en Paris en 1872. De modo que el Santos Vega costituye el único caso dentro de la gauchesca en que un autor de renombre reelaboró una de sus obras más conocidas después de transcurrir algo más de dos décadas, al cabo de las cuales justamente el género alcanzó su culminación. El análisis comparativo de ambas versiones constituye en consecuencia un rico material para estudiar, a través de un mismo autor y de un mismo tema, aspectos importantes relativos a la evolución histórica, literaria y lingüistica de la poesía gauchesca en el período en que ésta adquiere su mayor nivel.

Un documento de Ascasubi, de 1850, absolutamente desconocido hasta ahora, esclarece en forma categórica el sentido que le atribuía al poema en la época de su inicial gestación. "Su argumento - dicelo forman las costumbres de la campaña de Buenos Aires; su estilo es el lenguaje común de los habitantes de ella. Obra enteramente de costumbres, el autor ha elcgido para la acción un período que se refiere a los principios de este siglo, para no mezclar en sus cuadros incidentes relativos a las guerras civiles o discordias políticas".

Por cierto no corresponde aquí entrar en detalfes acerca de las diferencias que hay entre las ediciones de 1850 y 1872. Sólo digamos, en cuanto a lo exterior, que los 17 cuadros y 2,022 versos de la edición primigenia se convirtieron en 64 cuadros y 13,179 versos, lo cual es elocuente del muy apreciable desarrollo y ampliación que tuvo la obra respecto del plan original. En un libro de próxima aparición en Buenos

52 Hilario Ascasūbi, Paulino Lucero, cit., págs. 7-44. El título completo de esta composición es Jacinto Amores, gaucho oriental, baciendo a su paisano Simón Peñalva, en la colsta del Queguay, una completa relación de las fiestas civicas que para celebrar el aniversario de la jura de la Constitución oriental se bicieron en Montevideo en el mes de julio de 1833. 
Aires reeditamos por vez primera este olvidado texto de Ascasubi y lo ponemos al alcance de los estudiosos de la gauchesca, con anotaciones que señalan toidas las variantes que el autor introdujo en la versión definitiva del poema. ${ }^{53}$ Se demuestra allí que el texto de 1850 más que esbozo fue la génesis del conocido Santos Vega de 1872.

Ascasubi, a través de la anécdota o historia narrada en Santos Vega — "asunto lindo y largo", dirái él mismo en un verso- se propuso fijar como en un vasto daguerrotipo, en realidad laberinto folletinesco típicamente romántico, las características más vitales y aparentes de una singular sociedad campesina que precisamente comenzaba a desintegrarse en momentos en que terminaba el poema. En cuanto a la presencia del legendario payador Santos Vega debe seña!arse que no es la nota destacada en este poema ya que sólo desempeña el pasivo papel de narrador de los episodios que transcurren en el rudo ambiente pampeano. $Y$ si el Santos $V$ ega es una recreación histórica debe admitirse que en forma implícita encierra una interpretación. La visión que Ascasubi tiene de la vida rural bonaerense de fines del siglo xvirI y principios del XrX es casi idílica. Muestra con nostalgia vínculos paternalistas que si bien existieron en las estancias de Buenos Aires, han tenido su contrapartida en los gauchos no afincados, mano de obra ocasional, perseguidos como vagos y malentretenidos por el orden social imperainte.

Para concluir cabe recordar que Ascasubi, después del Pronunciamiento de Urquiza, en 1851, pasó de Montevideo a Entre Ríos, donde publicó varios folletos con poesías alentando la campaña contra Rosas. ${ }^{54}$ Después de Caseros se radica en Buenos Aires, pero pronto rompe con Urquiza y lo ataca con sus versos gauchescos, su arma de siempre. Las composiciones de esta época serían recopiladas más tarde en un volumen con el título de Aniceto el Gallo, gacetera prosista y gauchi poeta argentino. En los últimos años de su vida se establece en París. Allí, como ya hemos dicho, terminará su poema Santos Vega y editará en 1872 toda su producción poética en tres macizos tomos, su más perdurable monumento.

FéLIX WEINBERG

Universidad Nacional del Sur, Babia Blanca, Argentina

53 Félix Weinberg, La primera versión del "Santos Vega" de Ascasubi. Un texto gauchesco desconocido (en prensa).

54 Cfr.: Hilario Ascasubi, Poesía para el Pronunciamiento de Urquiza, compilación y prólogo de Manuel E. Macchi, Castellví, Santa Fe, 1956. 
